\title{
Examining risk factors associated with cardiovascular disease rates in children
}

\author{
Damien Byas*, Annette Hunter and Catherine Burger \\ North American Scientific Committee on Cardiovascular Health, USA
}

\begin{abstract}
In 2012, there were more than 17.3 million cardiac related deaths worldwide. Cardiovascular diseases were the main cause of death in almost all Organization for Economic Co-operation and Development (OECD) countries and accounted for 35\% of all deaths in 2009. Such research outcomes have assisted researchers in determining that additional emphasis should be placed on not only the examination of potential risk factors which may be associated with children's health outcomes, but also if health disparities may play a role in the quality of a child's health status and lifestyle. Cardiovascular disease (CVD) is now being studied as a health condition which not only significantly affects American children's groups, but this health outcome is now at the forefront of many public health research initiatives, which are investigating a possible link between CVD and other negative health outcomes which may be associated with high disease and mortality rates in children. In addition to examining the relationship between CVD and negative health outcomes among youth, research efforts are also in place to examine possible risk factors relative to one's genetic makeup, environmental influences, and behavioral patterns, which may be associated with CVD outcomes in children.
\end{abstract}

\section{Introduction}

In 2012, there were more than 17.3 million cardiac related deaths in worldwide [1]. CVD's were the main cause of death in almost all Organization for Economic Co-operation and Development (OECD) countries and accounted for $35 \%$ of all deaths in 2009 [2]. Sudden cardiac arrest (SCA) is a leading cause of death among adults over the age of 40 nearly worldwide. More than 350,000 Americans die annually of Sudden Cardiac Death (SCD), which attributes to about 680 persons every day of the year. One-half of the victims of SCD worldwide, are under the age of 65 [3]. The number of people who die each year from SCD around the world is roughly equivalent to the number who die from Alzheimers disease, assault with firearms, breast cancer, cervical cancer, colorectal cancer, diabetes, HIV, house fires, motor vehicle accidents, prostate cancer, and suicides combined [3]. Efforts are now underway to determine if there is a significant association between CVD prevalence and SCD outcomes.

The pathology of CVD begins early in life and progresses slowly. Evidence of atherosclerosis lesions identified in autopsy studies of young children, suggest an extended latent period prior to a diagnosis or cardiovascular event [4]. However, in 2016 CVD ranked number five for ages $1-4$, number six for ages $5-14$, and number 5 for ages 15 - 24 in the United States (CDC, 2018). An analysis of CVD trends in the United States, suggested that CVD will affect more than $45 \%$ of the population by 2035 [5].

Research continues to investigate preventative and treatment measures for CVD. Studies identified several CVD risk factors, including, but not limited to, obesity and sedentary behavior [6-8]. Given the pathology of CVD, it is imperative to identify and promote behaviors to decrease and eliminate risk factors in young children $[8,9]$.

\section{Purpose}

The purpose of this study was to examine specific identifiable risk factors which may be significantly associated with CVD outcomes in American children ( $N=422,599)$ (Kids' Inpatient Database (KID), Healthcare Cost and Utilization Project (HCUP), Agency for Healthcare Research and Quality (AHRQ, 2017). The sample group for this research study included American boys $(n=198,960)$ and girls $(n=$ 223,639 girls) between the ages of 4 and 12 years old. Based on the 2017 American Community Survey Single-Year Estimates, provided by the United States Census Bureau [10], it was determined that the sample adequately represented the population of American children from each socioeconomic level. Based on the approach applied to examine the target population of children stemming from various economic backgrounds, the researchers remained optimistic that the outcome of this research study could be applicable to regional and community initiatives which may target programs to reduce disease prevalence rates in children's groups, but more specifically CVD outcomes.

There is currently a very limited amount of research which examines potential identifiable risk factors which may directly attribute to CVD outcomes in children. The study will address both genetic and environmental factors which may have a potential influence on a child's health behavior and health choices.

\section{Method}

A random sample $(N=422,599)$ of American boys $(n=198,960)$ and girls ( $n=223,639$ girls) between the ages of 4 and 12 years, was analyzed for this research study. A chi square test for association was applied to determine if the factors of Healthcare Quality, Household Income, Race, and Gender may be associated with CVD prevalence

${ }^{*}$ Correspondence to: Damien Byas, North American Scientific Committee on Cardiovascular Health, USA, E-mail: dbyas@arizona.usa.com

Key words: diabetes, obesity, cardiovascular, children, disease

Received: October 02, 2018; Accepted: October 19, 2018; Published: October 26,2018 
in American children. $(a=.05)$. In addition to the application of the chi square test for association analysis, a Cramer's V statistical analysis was also conducted to examine the strength of association between cardiovascular disease prevalence and the four identifiable risk factors. The HCUP data examined in this research study provided to the United States Department of Health and Human Services, Agency for Healthcare Research \& Quality, from American hospitals which are located in 46 U.S. states [11].

\section{Results}

The results from this research study revealed that there were statistically significant associations between CVD and Healthcare Quality $\left(\mathrm{X}^{2}=14,238, p<.01\right)$, CVD and Household Income $\left(\mathrm{X}^{2}=\right.$ $223,121, p<.01)$, CVD and Race $\left(\mathrm{X}^{2}=5435.8, p<.01\right)$, and CVD and Gender $\left(\mathrm{X}^{2}=301,235, p<.01\right)$ in American children analyzed during the study (Table 1). These significant associations between CVD outcomes and the four identifiable risk factors in this study provide an indicator that factors Healthcare Quality, Household Income, Race, and Gender, are not independent of CVD outcomes in American children between the ages of 4 to 12 years.

In addition to significant chi square analysis results, additional analyses results revealed evidence of very strong significant associations between CVD outcomes and the factors of Healthcare Quality, Household Income, Race, and Gender (Table 2). The international standards for the Cramer's V strength of association analysis are provided (Table 3). Cramers $\mathrm{V}$ is referred to as a nominal measure of correlation and measured the data in this study for both levels and strength of association [12].

\section{Discussion}

Based on the results of this study, the researchers have concluded that factors of one's healthcare quality, socio-economic status, gender, and ethnic background, show strong correlations with CVD outcomes. Perhaps more extensive research on children's health related disparities may assist health professionals, communities, politicians, and other key

Table 1. Chi Square Test for Association: CVD $(a=0.05)$

\begin{tabular}{|c|c|c|}
\hline $\begin{array}{c}\text { Chi Square Test for } \\
\text { Association }\end{array}$ & CVD & Sig. \\
\hline Healthcare Quality & $\mathrm{X}^{2}=14,238$ & $* *$ \\
\hline Household Income & $\mathrm{X}^{2}=223,121$ & $* *$ \\
\hline Race & $\mathrm{X}^{2}=5435.8$ & $* *$ \\
\hline Gender & $\mathrm{X}^{2}=301,235$ & $* *$ \\
\hline
\end{tabular}

$*=$ Statistical Significance $\mathrm{p}<0.05$

$* *=$ Statistical Significance $\mathrm{p}<0.01$

NS $=$ Not Statistically Significant

Table 2. Cramer's V Analysis for Strength of Association

\begin{tabular}{|c|c|}
\hline Cramer's V Analysis & CVD \\
\hline Healthcare Quality & 0.959 \\
\hline Household Income & 0.675 \\
\hline Race & 0.956 \\
\hline Gender & 0.955 \\
\hline
\end{tabular}

Table 3. Standard for Cramer's V Coefficients

\begin{tabular}{|c|c|}
\hline Levels of Association & Strength of of Association \\
\hline$<0.10$ & Weak \\
\hline 0.11 to 0.30 & Moderate \\
\hline 0.31 to 0.35 & Strong \\
\hline$>0.35$ & Very Strong \\
\hline
\end{tabular}

stakeholders in developing strategies which may be applied to reduce both health disparities and disease prevalence for American youth.

In order to reduce or eliminate behaviors that contribute to heart disease in children, preventive measures will need to be implemented to ensure quality health outcomes in children. Parents or guardians can foster healthy growth and development in their children through nutritious eating habits [13-16]. As a result, eating healthy will provide children with the nutrients and calories needed for growth and development thereby decreasing fat intake and reducing the possibility of atherosclerosis and other gateway factors which may be associated with heart disease $[16,17]$. Parents or guardians can also promote and encourage a healthy lifestyle with children through daily exercise [13]. Daily exercise consisting of about 60 minutes of moderate to vigorous physical activity, can assist in the prevention of heart disease in children [15] and to further support the prevention of heart disease in children at a young age, parents or guardians can model good sleeping habits to children [16].

While parents or guardians play a significant role in helping children in the prevention of heart disease, it must be mentioned that healthcare providers may also contribute largely to assisting in the prevention of heart disease in children [18]. It is recommended that healthcare providers evaluate the physical activities and inactive behaviors of children at every child-wellness visit $[13,18]$. Although at this present time, a valid and reliable instrument is not available to healthcare workers, healthcare workers can still monitor a child's health status and well-being by asking a parent or guardian questions and performing regular health screenings in order to remain well-informed of any major changes in health outcomes for children $[17,18]$.

In addition, it is recommended that more educational and community-based programs be implemented to reach parents, guardians, community officials, and children outside of traditional healthcare environments to advocate for prevention of childhood heart diseases [19]. Educational and community-based programs can be employed in such settings as schools, community centers, and churches. The goal of the educational and community-based programs is to operate under nontraditional healthcare settings that will foster and promote frequent informal communications and knowledge sharing within schools and communities through social interactions on the prevention of heart diseases in children [19]. Although the programs will be an excellent source in providing information to parents, guardians, and children, it is important that information provided is communicated on the level of a child's understanding in hopes of encouraging and inspiring children to consciously adopt positive behavioral changes for their health [20-22].

\section{References}

1. The Heart Foundation. (2016) Heart Disease: Scope and Impact. Retrieved from: http:// www.theheartfoundation.org/heart-disease-facts/heart-disease-statistics/

2. Organisation for Economic Co-operation and Development (2015) Cardiovascular Disease and Diabetes: Policies for Better Health and Quality of Care: OECD Health Policy Studies.

3. Sudden Cardiac Arrest Foundation (2017) Sudden Cardiac Arrest: A Healthcare Crisis Retrieved from: http://www.sca-aware.org/about-sca

4. Furtado JM, Almeida SM, Mascarenhas P (2018) Anthropometric features as predictors of atherogenic dyslipidemia and cardiovascular risk in a large population of schoolaged children. PLoS One 13: e0197922. [Crossref]

5. Benjamin EJ, Virani SS, Callaway CW, Chamberlain AM, Chang AR, et al. (2018) Heart Disease and Stroke Statistics-2018 Update: A Report From the American Heart Association. Circulation 137: e67-67e492. [Crossref] 
6. Becher H, Palm F, Aigner A, Safer A, Urbanek C, et al. (2016) Socioeconomic Conditions in Childhood, Adolescence, and Adulthood and the Risk of Ischemic Stroke. Stroke 47: 173-179. [Crossref]

7. Puolakka E, Pahkala K, Laitinen TT (2016) Childhood Socioeconomic Status in Predicting Metabolic Syndrome and Glucose Abnormalities in Adulthood: The Cardiovascular Risk in Young Finns Study. Diabetes Care 39: 2311-2317. [Crossref]

8. Umer A, Kelley GA, Cottrell LE, Giacobbi P Jr, Innes KE, et al. (2017) Childhood obesity and adult cardiovascular disease risk factors: a systematic review with metaanalysis. BMC Public Health 17: 683. [Crossref]

9. Silva DR, Werneck AO, Collings PJ, Fernandes RA, Barbosa DS, et al. (2017) Family history of cardiovascular disease and parental lifestyle behaviors are associated with offspring cardiovascular disease risk markers in childhood. Am J Hum Biol 10: 29. [Crossref]

10. CDC/National Center for Health Statistics/Office of Analysis and Epidemiology (2018) Health, United States, 2017 - Data Finder. Atlanta, Georgia: Centers for Disease Control and Prevention.

11. HCUP Kids' Inpatient Database (KID) Healthcare Cost and Utilization Project (HCUP) (2017) Agency for Healthcare Research and Quality.

12. Cramér H (1946) Mathematical Methods of Statistics. Princeton: Princeton University Press. ISBN 0-691-08004-6.

13. American Heart Association (2018) How to help prevent heart disease at any age. Retrieved from https://www.heart.org
14. Story M, Kaphingst KM, Robinson-O’Brien R, Glanz K (2008) Creating healthy food and eating environments: policy and environmental approaches. Annu Rev Public Health 29: 253-272. [Crossref]

15. University of Rochester Medical Center (2018) Prevention of heart disease starts in childhood. Retrieved from https://www.urmc.rochester.edu

16. US National Library of Medicine (2018) How to prevent heart disease. Retrieved from https://medlineplus.gov.

17. Mayo Foundation for Medical Education and Research (2018) Strategies to prevent heart disease. Retrieved from https://www.mayoclinic.org.

18. Daniels SR, Pratt CA, Hayman LL (2011) Reduction of risk for cardiovascular disease in children and adolescents. Circulation 124: 1673-1686. [Crossref]

19. Office of Disease Prevention and Health Promotion (2018) Educational and communitybased programs. Retrieved from https://www.healthypeople.gov

20. Benjamin EJ, Blaha MJ, Chiuve SE, Cushman M, Das SR, et al. (2017) Hear Disease and Stroke Statistics-2017 Update: A Report From the American Heart Association. Circulation 135: e146-146e603. [Crossref]

21. US Census Bureau (2018) New American Community Survey Statistics for Income, Poverty and Health Insurance Available for States and Local Areas. Statistics for More Than 40 Demographic and Economic Topics Provide Detailed Profiles of Communities Nationwide.

22. Davis K (2016) What's to know about sleep deprivation? Medical News Today Retrieved from https://www.medicalnewstoday.com

Copyright: (C2018 Byas D. This is an open-access article distributed under the terms of the Creative Commons Attribution License, which permits unrestricted use, distribution, and reproduction in any medium, provided the original author and source are credited. 